This item was submitted to Loughborough's Research Repository by the author.

Items in Figshare are protected by copyright, with all rights reserved, unless otherwise indicated.

\title{
An investigation of Physics undergraduates' attitudes towards mathematics
}

PLEASE CITE THE PUBLISHED VERSION

http://teamat.oxfordjournals.org/content/29/3/140.short

\section{PUBLISHER}

Oxford University Press on behalf of The Institute of Mathematics and its Applications $\odot$ The Author

\section{VERSION}

AM (Accepted Manuscript)

\section{LICENCE}

CC BY-NC-ND 4.0

\section{REPOSITORY RECORD}

Symonds, Ria, Duncan Lawson, and Carol L. Robinson. 2019. "An Investigation of Physics Undergraduates' Attitudes Towards Mathematics". figshare. https://hdl.handle.net/2134/8783. 
This item was submitted to Loughborough's Institutional Repository (https://dspace.lboro.ac.uk/) by the author and is made available under the following Creative Commons Licence conditions.

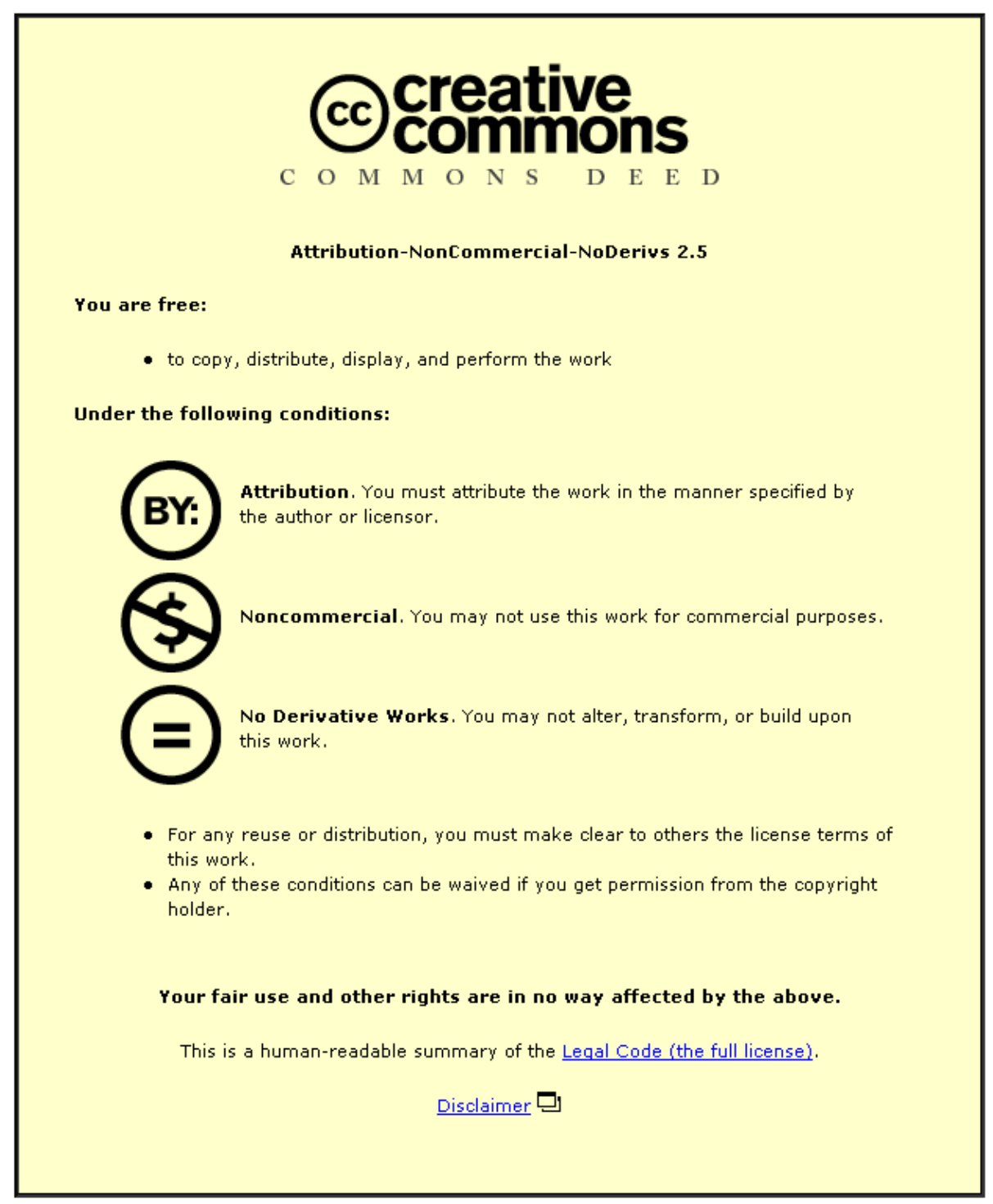

For the full text of this licence, please go to: http://creativecommons.org/licenses/by-nc-nd/2.5/ 


\title{
An investigation of Physics undergraduates' attitudes towards Mathematics
}

\author{
RIA SYMONDS $^{\mathrm{a}^{*}}$, DUNCAN LAWSON ${ }^{\mathrm{b}}$ and CAROL ROBINSON ${ }^{\mathrm{c}}$ \\ ${ }^{\mathrm{a}}$ University of Nottingham, UK; ${ }^{\mathrm{b}}$ Coventry University, UK; ${ }^{\mathrm{c} a}$ University of Loughborough
}

In recent years, the failure rate on first year mathematics modules on Physics courses at Loughborough University has given cause for concern. It was feared that failure in the first year would result in students performing poorly in future mathematics modules. Hence, a proactive support system was introduced for the mathematically less well-prepared first year Physics students in October 2005. On completion of the first mathematics module, this initiative showed some successful features in terms of the results of the less well-prepared students. However, the use of qualitative research methods revealed a difference in attitudes towards mathematics between the wellprepared and less well-prepared students. This paper outlines the students' attitudes towards mathematics expressed through questionnaires and individual interviews. It compares the well-prepared and less well-prepared students' attitudes towards mathematics prior to university and discusses the differences between the two cohorts. The paper also examines how the introduction of a support system has affected the students' attitudes. A key outcome, in terms of the less well-prepared students, is that the first semester experience was positive in terms of increasing enjoyment of mathematics, but was negative in terms of feeling confident in mathematics. Finally, the paper also analyses data taken from individual interviews with some students on students' learning approaches towards mathematics. These are investigated closely and comparisons are again made between the well-prepared and less well-prepared students. The analysis reveals that the less well-prepared students failed to adapt their learning approach to one suitable for Higher Education.

Keywords: Attitudes; Mathematics; Learning Approach

*Corresponding author. School of Mathematical Sciences, Pope Building, University of Nottingham, University Park, Nottingham, NG7 2RD

Email: Ria.Symonds@nottingham.ac.uk 


\section{Background}

Mathematics is often viewed as a difficult and unpopular subject amongst students and it is a common conception amongst teachers and mathematics researchers that attitudes towards mathematics have an effect on student achievement. Since Feierabend's "Review of Research of Psychological Problems in Mathematics Education" (1960), an increasing number of published articles that examine the effects of students' attitudes and beliefs in mathematics has emerged. Aiken (1976) organised a scale of Attitudes Towards Mathematics (ATM) to investigate the effects of students' attitudes. This scale has been widely accepted by researchers who study attitudes towards mathematics, because it is an instrument that measures only the attitude towards the subject itself, disregarding the teacher's performance or the type of mathematical activity proposed. A more recent ATM scale, designed by Tapia \& Marsh (2004), is a shorter instrument with a straightforward factor structure designed to investigate the underlying dimensions of attitudes toward mathematics. These studies have found that positive attitudes (i.e. feelings of enjoyment, confidence and success) towards mathematics are associated with high performance in the subject. Similar findings have been reported by McLeod (1992), Gal et al (1997) Ruffell et al. (1998) and Galbraith \& Haines (1998). In a study by Ma (1997), data from a Dominican national evaluation of high school mathematics was analysed and it was found that "...[the] interactive nature between attitude toward mathematics and achievement in mathematics can substantially modify their causal relationship." In another study by Utsumi \& Mendes (2000), 209 students from private education in Brazil responded to an ATM scale and a questionnaire. Results indicated that as the self-perception of mathematical performance improved a more positive attitude towards mathematics emerged. In these studies, a number of factors that affect attitudes towards mathematics, such as enjoyment, value and confidence were investigated. Therefore, the data in this study shall be analysed with reference to these attitudinal factors. It should also be noted that, unlike these reports, this paper shall analyse and compare the attitudes of students, depending upon their mathematical preparedness on entry to university.

Whilst the study of attitudes to mathematics is well-developed, mathematics confidence is much more in its infancy as a topic of study. Indeed, there is no commonly agreed definition of mathematics confidence makes it difficult to distinguish between and analyse students. Galbraith and Haines (1998, p278) believe students with mathematics confidence "obtain value for effort, do not worry about learning hard topics, expect to get good results, and feel good about mathematics as a subject”. Likewise, Pierce et al. (2005) take a similar view, associating confidence with ability and assurance in mathematics. In this paper, mathematics confidence shall partly be recognised by a student's belief in being able to 'do' mathematics. Also, if a student appears to excessively worry about mathematics, feels naturally weak at mathematics or feel mathematics is too difficult then that student shall be recognised as lacking mathematics confidence.

\section{Introduction}

Like many other universities across the UK, Loughborough University has recognised a serious decline in students' mathematical preparedness on entry to their degree courses. Commonly known as the "Mathematics Problem" (Sutherland and Pozzi 1995, LMS, IMA \& RSS 1999), this growing problem has affected pass rates in 
mathematics modules within departments across Loughborough University, and, moreover, this may have affected the students' perception of mathematics at university. Loughborough University has over 16,000 undergraduate and postgraduate students and has a growing reputation as one of the UK's leading universities. In 2005, its Mathematics Education Centre was awarded Centre for Excellence in Teaching and Learning status by the Higher Education Funding Council of England. This joint award, with the Mathematics Support Centre at Coventry University, was for its university-wide support in mathematics and statistics. The proactive initiative described in this paper is one of many initiatives introduced by the Centre.

In recent years there has been a growing failure rate on the mathematics modules within the Physics department at Loughborough University. A mathematics support initiative was put into place in October 2005 in order to support students who had been deemed (by virtue of their previous mathematics qualification) as being mathematically less well-prepared. In England, traditionally students on Physics and Physics related courses will study A-level mathematics prior to university. In A-level they can achieve a pass grade A-E (where A denotes the highest pass grade and $\mathrm{E}$ the lowest pass grade). In recent years, students with non-traditional backgrounds (such as vocational qualifications or AS-level Mathematics) have been enrolled. The less well-prepared students were identified as those with Mathematics A-level D and E grades or an AS level (equivalent to half an A-level) Mathematics and those who had vocational qualifications. A group of twenty-five students was taught separately, from the mainstream group (consisting of thirty-eight students), for the entirety of the first mathematics module. These students were given an extra hour a week teaching time and a different teaching approach and different teaching materials were used. However, the same assessment methods were used with both groups. On completion of the first mathematics module, the initiative showed some success in terms of results. The pass rate of the less well-prepared students had been 48\% in 2004-05 and this rose to 67\% in 2005-06 when the support was introduced, Symonds et al (2006). However, the use of qualitative research methods has uncovered a difference in attitudes towards mathematics between the well-prepared and less well-prepared students, and a lack of mathematics confidence amongst the less well-prepared students, despite the intervention.

In this paper, we discuss the outcomes of a questionnaire, given to the first year Physics students on completion of their first mathematics module. The data is anlaysed to determine the students' attitudes towards mathematics prior to university. Further analysis is carried out to investigate if the introduction of a support system has affected the students' attitudes. This is followed by a detailed analysis of the responses given during a series of follow-up interviews, conducted towards the end of the second mathematics module. The interviews were carried out in order to conduct a deeper investigation into the students' attitudes and the issue of mathematics confidence. Analysis of this data investigates how students adapted to university and, in particular, examines their learning approaches to mathematics. A comparison of the responses of the well-prepared students and less well-prepared students is made throughout. 


\section{Questionnaire}

\subsection{Distribution}

On completion of the first semester mathematics module (February 2006), a questionnaire was distributed to the first year Physics students designed to investigate the students' attitudes towards mathematics prior to university and to examine whether the support system had had an impact on the attitudes of the less wellprepared students. The questionnaire also sought to examine the students' attitudes towards the assessment methods for the mathematics module.

Since not all students who took the mathematics module in semester 1 take the follow on module in semester 2, different means of distributing the questionnaire were used, as shown in Figure 1. It can be seen that the questionnaire was distributed to 63 students in total. The questionnaire was distributed to the 47 students, who were registered for the second mathematics module, during a lecture slot for the second mathematics module during Week 1 of the second semester. Since a lecture slot was chosen during the first week of the new term, it was anticipated that attendance numbers would be substantial. For the remaining 16 students, who were not taking the second semester module, the questionnaire was mailed into their departmental pigeon holes.

Figure 1: How the questionnaire was distributed to the Physics students.

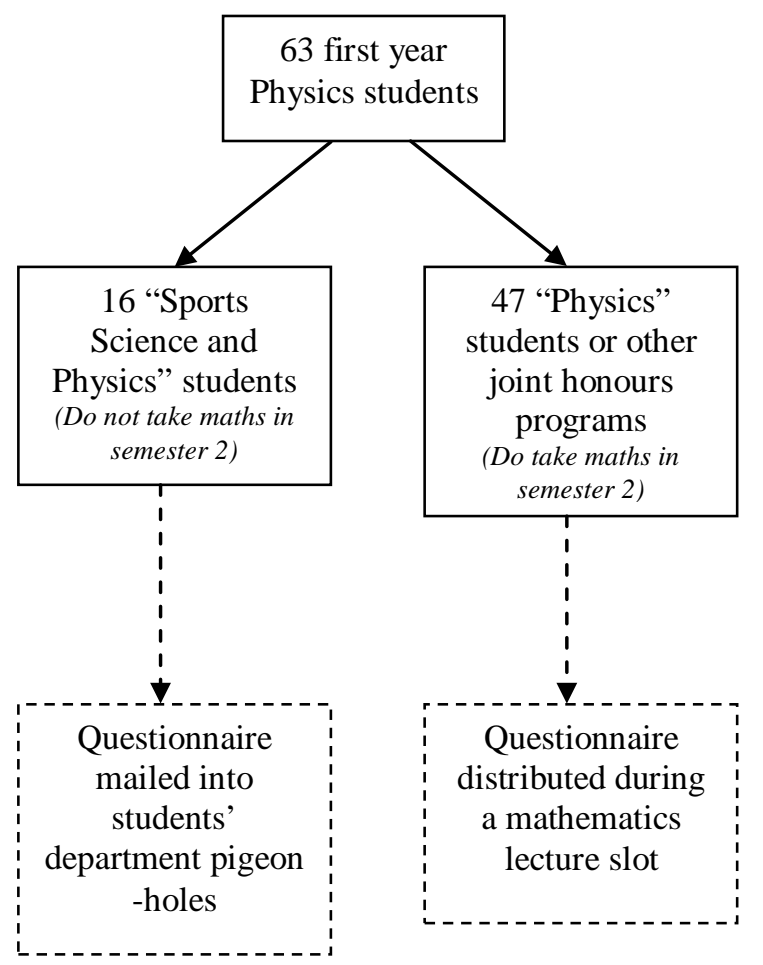

Once the questionnaire had been distributed, both by hand during the lecture and by post to the pigeon holes, and replies had been received, it was recognised that poor attendance had resulted in a small number of responses (29 out of 63 possible replies, 10 (out of 25) from the less well-prepared (LWP) group, 19 (out of 38) from the wellprepared (WP) group). Therefore, in order to receive additional replies the questionnaire was mailed into the remaining students' departmental pigeon holes during week 2 of semester 2. This resulted in seven more replies (3 from LWP 
students and 4 from WP students). Therefore, 36 out of 63 possible replies were received, which accounted for $57 \%$ of the students who were originally registered for the first module. Of these replies 13 (out of 25 i.e. 52\%) were from the LWP group and 23 (out of 38 i.e. 61\%) were from the WP group. It should be noted that the questionnaire was completed before the students were aware of their examination marks for the first mathematics module. Therefore, the students only had their own ideas of how they had performed in the module.

\subsection{Analysis}

In this section, the responses to some questions from the questionnaire are studied in detail. The first questions that will be analysed asked the students for their attitudes towards mathematics prior to university and after their first semester of university. The next question asked for the students' attitudes towards the first mathematics module. And the last question asked for their perceptions of the exam assessment for this module. Analysis of these questions will be used to determine whether the support system had an impact on the students' attitudes.

3.2.1 Attitudes towards Mathematics prior to / whilst at university After the students had provided their personal details, the first question on the questionnaire was designed to identify the students' attitudes towards their mathematics education prior to university. The students were given two statements ("I enjoy maths" and "I feel confident with maths") and subsequently asked to tick the statements which they felt applied to their education prior to university. The same question was asked at the end of the questionnaire but the students were asked to indicate which of the statements applied to their university education (in both cases the students could chose none, one or both of the statements). It was anticipated that these questions would reveal an insight into the student perspective of mathematics prior to university that could be compared to their perspective of mathematics after the first semester. However, it should be noted that responses to the pre-university question could have been subconsciously influenced by the students' experience at university.

Table 1 shows the percentage of students who chose each response. The wellprepared students and less well-prepared students are compared within the table. Analysis of the students' responses reveals that the well-prepared students' responses differ from those of the less well-prepared students. The data in Table 1 reveal that, prior to university, the majority of well-prepared students enjoyed mathematics and felt confident with mathematics. In comparison, less than half of the less wellprepared students felt confident with mathematics and even fewer, less than a third, enjoyed mathematics. Each of the responses received a lower response rate from the less well-prepared students in comparison to the well-prepared students.

Table1: Students' responses in relation to their attitudes to mathematics before and during university.

\begin{tabular}{|c|c|c|c|c|}
\hline \multirow[b]{2}{*}{ Response } & \multicolumn{2}{|c|}{$\begin{array}{c}\text { \% of less well-prepared who } \\
\text { chose each statement } \\
\text { (13 students) }\end{array}$} & \multicolumn{2}{|c|}{$\begin{array}{l}\text { \% of well-prepared who chose } \\
\text { each statement (23 students) }\end{array}$} \\
\hline & Prior to uni & At uni & Prior to uni & At uni \\
\hline I enjoy maths & $31 \%$ & $46 \%$ & $57 \%$ & $57 \%$ \\
\hline I feel confident with maths & $46 \%$ & $31 \%$ & $57 \%$ & $65 \%$ \\
\hline
\end{tabular}


The data in Table 1 shows that, prior to university, there is a greater feeling of enjoyment of mathematics amongst the well-prepared group compared to the less well-prepared group (by 26 percentage points), but a much smaller difference between the two groups is in terms of their confidence (where the gap is only 11 percentage points).

The first semester experience has a marked effect on the difference between the two groups since the gap in enjoyment reduces by 13 percentage points.This suggests that the support system for the less well-prepared students has had a positive effect, particularly in increasing the overall level of enjoyment of mathematics in this group. However, the impact of the first semester on confidence is very different. Prior to university the gap between the less well-prepared and well-prepared groups was only 11 percentage points. After the first semester this has risen to 34 percentage points. So, although the less well-prepared students are growing (comparatively) in enjoyment, their confidence is dropping rapidly. This suggests that there is an, as yet, unidentified factor contributing to their lack of confidence.

3.2.2 Feelings Towards the Module and the Exam Assessment This section will examine how the students perceived the mathematics module and the assessments of the module. In order to investigate the issue of confidence further, analysis of the responses with regards to the module and exam will now be discussed. Table 2 shows the responses by the students in relation to the mathematics module and the mathematics exam. A five-point Likert scale was used so the percentages in Table 2 relate to the proportion of students who had chosen the responses "I agree" or "I strongly agree”. (It should be noted that only 12 students from the LWP group responded to these questions).

Table 2: Students responses in relation to how they felt about the first year mathematics module and the exam assessment.

\begin{tabular}{llcc}
\hline Question & Response & $\begin{array}{l}\text { \% of less well-prepared } \\
\text { who agreed with each } \\
\text { statement }\end{array}$ & $\begin{array}{l}\text { \% of whepared } \\
\text { who agreed with each } \\
\text { statement }\end{array}$ \\
\hline \multirow{2}{*}{ Module } & Enjoyed module & $83 \%$ & $48 \%$ \\
& Felt confident in topics covered & $58 \%$ & $65 \%$ \\
Exam & Felt prepared & $33 \%$ & $65 \%$ \\
& Felt confident with performance & $25 \%$ & $52 \%$ \\
\hline
\end{tabular}

In comparison to the well-prepared students, the less well-prepared students responded far more positively towards the enjoyment of the mathematics module. Since $83 \%$ of the less well-prepared students indicate that they enjoyed the module, compared to $46 \%$ who enjoy mathematics at university (Table 1), this provides further evidence of the value of the support system. Furthermore, these students indicated that they had felt much more confident in the mathematics topics covered by the module (58\%) in comparison to their general feelings of mathematics confidence (31\%, Table 1).

However, the apparent lack of confidence exhibited by the less well-prepared students (in Table 1) can also be seen from these responses (in Table 2), and in particular their confidence in their exam attempt. (It should be noted that five out of the 12 less-well 
prepared students had failed the exam, although they were not aware of thiswhen completing the questionnaire).

Only $25 \%$ of the less well-prepared students indicated that they had felt confident with their exam attempt. Since $58 \%$ of the less well-prepared students felt confident with the mathematics topics covered by the module, the data suggests that the lack of confidence amongst these students has been largely affected by the exam assessment.

A detailed examination of the three less well-prepared students, who indicated that they had felt prepared for the exam, reveals that only one student had not performed well in the exam. Although this student had felt confident with his exam attempt, he had failed this assessment and, consequently, the module. However, since this student had performed well in the coursework it may be that this success helped to create the feeling of confidence. In general, the data suggests that the lack of mathematics confidence, amongst the less well-prepared students, is affected by the exam assessment. Since the less well-prepared students achieved good coursework marks (a group average of 58.3\%, compared to an average of 58.7\% amongst the well-prepared students), this could explain the increase in responses with regards to a feeling of confidence. Therefore, it is likely that the exam assessment has had an effect on the less well-prepared students' general feelings of mathematics confidence.

To summarise, the data from the questionnaire shows that the support system has been positive in terms of the less well-prepared students' attitudes towards mathematics. In particular, there is an increase in feelings of enjoyment of mathematics generally and of the module. However, feelings of confidence amongst the less well-prepared students have decreased since being at university. Further analysis shows that the exam assessment is a likely cause of this undermining of confidence of the less well-prepared students.

\section{Follow-up interviews}

In order to investigate further the students' attitudes towards mathematics and, in particular, to determine if the mathematics module exam had primarily affected the students' feelings of mathematics confidence, it was decided that a number of students, who had failed the module, would be interviewed. In addition, analysis of the interview data revealed the underlying issue of how well the students had adapted to mathematics at university. This will be examined in detail, paying particular attention to the learning approaches that the students adopted.

\subsection{The participants}

An e-mail was sent during Week 4 of Semester 2, to the 17 students who had failed the mathematics module, requesting volunteers to participate in individual interviews. However, only 1 student responded to the e-mail. Another e-mail was sent during Week 5 of Semester 2 in order to encourage more participants, however this proved unsuccessful and no more students were willing to be interviewed. This apparent lack of willingness to share the student perspective may indicate that the students who had failed the mathematics module were not comfortable in discussing their thoughts about mathematics or their ability in this subject.

Further attempts to encourage participation were carried out by targeting students who had taken part in preliminary interviews at the start of the mathematics module. These students were e-mailed individually and were also approached during a tutorial session. Finally, six students agreed to participate in an interview, in addition to the 
one student who had responded previously. It should be noted, that students were able to withdraw from the study at any point.

Due to the way in which the students were recruited, not all students who were interviewed had failed the module. Out of the seven students, one student was deemed as being well-prepared and had achieved $92 \%$ in the first mathematics module. The remaining six students were deemed as being less well-prepared, three of them had failed the first semester module, two had passed but had achieved marks close to the pass mark (40\%) and one student had performed well with a mark of $73 \%$.

\subsection{The interviews}

The students were interviewed during Weeks 11 and 12 of the second Semester at which time they were due to complete the second mathematics module. Each interview lasted for approximately 20-30 minutes. The interviews were semistructured and open-ended questions were put to the participants. All sessions were audio taped. One of the authors of this paper, Symonds, carried out the interviews and transcribed the audio recordings. This author also carried out the analysis of each discussion.

Each participant was asked the same questions, which concentrated on a number of issues which the researcher wished to investigate. These issues were categorised into the students' previous mathematics experience, their learning of mathematics and their feelings towards their mathematics module marks and the assessment methods. The results from the interviews will be discussed using these issues. As in previous sections, a comparison of the responses from the well-prepared student (WP 1) will be made against the responses from the less well-prepared students (LWP 1-6).

\subsection{Analysis}

The interviews were transcribed and analysed thematically using Atlas-ti qualitative analysis software (www.atlasti.com). This involved assigning relevant quotes to categories initially generated by the researcher (as discussed above), which focused on the students' general attitudes to mathematics and comparing this with their attitudes towards their university mathematics modules. These categories were explored repeatedly within the transcripts and the connections between them revealed notable differences between the attitudes and learning approaches of the less wellprepared students and the well-prepared student. This is discussed in detail and accompanied by illustrative quotes below.

3.3.1 Previous mathematics experience. The seven students interviewed exhibited various mathematical backgrounds. The well-prepared student had achieved an Alevel grade B in Mathematics. However, his school had adapted some A-level classes so that they were given in a lecturing environment, so as to ease the transition from school to university. The student's perceptions expressed during the interview, is that this experience undoubtedly helped him to cope with university mathematics.

WP 1: “...in the end the maths had gotten really tedious at A-level because it wasn't done in a lecturing environment ... but when I came to university it was all ok again because it's all in a lecture environment and that's really nice and straightforward." 
In addition, this student expressed a positive attitude toward mathematics and felt confident in his own mathematical ability, to such an extent that he wished to take the optional mathematics module in his second year.

Likewise, the less well-prepared students' mathematical backgrounds also appear to have affected their attitudes towards mathematics. Out of the six less well-prepared students, two were mature students who had not taken A-level mathematics. Due to their recent lack of experience with mathematics, these students expressed a lack of confidence in their mathematical abilities. The two students had entered university fearful of the prospect of mathematics and felt comparatively weaker in the subject compared to their peers, as illustrated by this student:

LWP 6: "Because I didn't have the A-level background I found that the maths side of it really really frightened me ... I have always felt this way, particularly with maths, that I'm ten steps behind everyone else.”

One other less well-prepared student expressed similar negative feeling towards mathematics due to his previous performance in his A-level mathematics.

LWP 3: "I didn’t get on with it at A-level and I just haven’t liked it since, in all fairness.”

However, the remaining three students (two of whom passed the module) expressed a fondness towards mathematics. These students had had a positive experience in their mathematics education, prior to university, and this seemed to reflect their personal views of mathematics.

LWP 1: "I enjoyed it [maths] more at school but that's more because in the second year I was just re-sitting AS so I got 4 lessons a week in that class. The atmosphere was amazing, because there was only about 5 of us.”

This student had initially struggled with mathematics at AS-level and as a result he had to re-sit the year. Consequently, his subsequent mathematics classes were taught in a small group of a similar ability. This approach created an enjoyable learning environment for the student and consequently his experience of school mathematics was an enjoyable one.

3.3.2 Learning of Mathematics. During the interviews the students were asked how they had approached the learning of mathematics. The students' responses suggested that the well-prepared student was able to adapt to a new way of learning mathematics, whilst at university, whereas the less well-prepared students found this transition more difficult. However, it should be noted that the well-prepared student may not be representative of this cohort of students. Nevertheless, this student revealed a high understanding of what was required in order to perform well in the mathematics modules. His A-level experience had contributed to this, and as a result he felt that a good set of notes was essential;

WP 1: "I make a really good set of notes ... I can always look back at them, that's the best thing. And sometimes I do need to look back at them, every now and again. And there's always examples and stuff like that.”

This student also described how he had made full use of the tutorial sessions and would complete the worksheets each week so that "it's fresh in your mind and it helps to reinforce it". Moreover, the student understood that in order to learn effectively he needed to make use of a range of resources. For example, when this student had struggled with a difficult mathematical topic he described how he had used the Internet and sought help from his lecturers to gain a better understanding of the 
problem. It appears that this well-prepared student possessed good study skills since he was aware of and monitored his own learning processes to ensure success.

In comparison, it appears that the less well-prepared students failed to cognitively analyse their mathematical performances. That is that they lacked metacognitive skills, Flavel (1976). Five out of the six students were regular attendees to lectures and tutorials, however all six students were aware that they had not worked hard enough during their time at university and that more effort was required. Unlike the well-prepared student, the less well-prepared students failed to monitor and direct their own learning of mathematics during their first semester. Consequently, their learning strategies were generally unsuccessful. The following comments are representative of the less well-prepared students who were interviewed:

LWP 4: "I probably should have worked a lot harder ... I'm not gonna go out of my way to look stuff up."

LWP 5: "You can't learn maths without doing the problems ... but I've been really lazy. I don't do any work when I go home.”

LWP 1: "I didn’t really put in enough effort in the first semester. I should have done more work basically.”

Although these students were aware that in order to perform well they needed to apply themselves and continually practise the mathematics, many of the students did not do this in practice. Arguably, the difference between the well-prepared and less well-prepared students is not only the number of hours they put into their studies but also the amount of reflection they engage in as learners and their understanding of their positions as learners. By their own admission, these students did not engage well in practising the mathematics and it is possible that, at that time, they were not aware that their learning strategies required change. Persisting with learning strategies that had previously been unsuccessful may have been the main reason why these students did not perform well in the mathematics module. Similarly, Hofer and Pintrich (2002) have reported thatstudents' conceptions of knowledge and learning ('personal epistemologies') are related to their educational achievements.

When the students were asked why they had not worked harder the common response was due to laziness or a lack of motivation. In particular, one student expressed:

LWP 5: “...you're not under the same constraints as you are at school. You're more relaxed; it's up to you whether you do the work. You're not driven by the lecturers like you are by the teachers.”

This comment illustrates the notion that the less well-prepared students find it difficult to adapt to the new way of learning at university. Without the direction provided by a teacher, it appears that the less well-prepared students find it hard to motivate themselves to work. In addition, it is possible that the students lack an understanding of the rules, assumptions and goals of the undergraduate community of practice (Wenger, 1998). The support of a 'teacher' can help a student understand the new community of practice, however, since this kind of support is lacking at university this impedes a student's ability to understand what is required. Since the less well-prepared students do not appear to spend time reflecting on their own learning and they do not have direction from a teacher then the students may fail to adapt their learning strategies in a way required to succeed in the new environment.

Another commonality between the less well-prepared students was their reliance of help from their peers. 
LWP 6: “I'm more daunted by working on my own because I'm completely convinced that I can't do things, a lot of the time... I work better with other people, certainly, because you've got instead of just the stuff in my head, you've got the stuff from other people's.”

LWP 4: “...if you're doing coursework and you don’t know I'll ask [name] how do we do this?', or in the tutorials I'll ask him.”

When asked about what support the student used:

LWP 2: “...support from the lecturers, support from in here [Mathematics Learning Support Centre], my other classmates.”

Again, in terms of these students, these comments reinforce the analysis of a lack of mathematics confidence amongst the less well-prepared students since they depend upon the help and support of their peers and others in order to tackle mathematics problems with some amount of confidence. It appears that, since the close support of a teacher is lacking at university and that many less well-prepared students are used to relying on some form of direction from a teacher, the students turn to their peers for such direction. However, in this case, the less well-prepared students seek help from each other (as revealed by the students in the interviews), which proves unsuccessful since most of the students have failed to change their learning approach to mathematics. Similar findings have been reported by other researchers. For example, Macrae, Brown and Rodd (2003), in an ESRC study: Student's Experiences of Undergraduate Mathematics, found that failing students frequently socialised with other failing students. Moreover, these students conveyed a general lack of motivation, which was reinforced by their peers. In hindsight, grouping the less wellprepared students together in the support programme could have helped to nurture these friendships.

In addition, three students, two of whom had failed the module, revealed that their approach to revising for the end of term exam was also unsuccessful. These students expressed how they had either learnt only the basics of topics or only those topics that they had felt confident with;

LWP 1: "The revision I had done, was just the basics really."

LWP 3: “There was a lot of topics and I couldn't revise them all. I probably did the easy bits of all the topics, and then when it came to the questions all the marks were at the end and I thought 'I don't know how to do that bit', and that was it."

LWP 6: "I find the bits that I'm comfortable with and hopefully the bits that are worth the most marks generally on [the] paper."

Since the students had failed to change their learning approach for university mathematics, they found that they were not able to revise all the material for the exam. This could also be a legacy from their previous mathematics experience. It is possible that the less well-prepared students did not achieve a higher mathematics qualification since they used this strategy of only learning topics that they felt comfortable with. However, by only learning the basics, the less well-prepared students proved unsuccessful, once again, in their learning approach to mathematics. This could cause repercussions in the second year, since students will require a full understanding of the mathematics from their first year for their future modules.

Finally, another comment from a student revealed that other factors may have also contributed to a lack of effort amongst the less well-prepared students.

When asked why he did not work harder:

LWP 1: "I think it's just because of it being the whole first semester and every night going out and it's like maths, nah.” 
Again, this comment reinforces the notion that the less well-prepared students have failed to adopt a successful learning approach. It appears that this student felt that the first semester was an opportunity for socialising and this was more attractive than spending time doing mathematics. It may be that he felt that, because it was the first semester, the mathematics that was being covered would be quite straightforward.

It is possible that the students' attitudes towards mathematics have had an impact on the way in which the students approach their learning. On entry to university, the less well-prepared students did not particularly enjoy mathematics. Therefore, it is possible that due to this negative attitude the less well-prepared students had no strong desire to learn mathematics, which in turn affected the way in which they approached their learning of mathematics. This supports findings from other researchers, for example OECD (2004), whereby the adoption of an effective learning strategy is dependent upon the students' attitudes and dispositions towards mathematics.

3.3.3 Feelings Towards Module Marks and Assessments. During the interviews the students were asked how they had felt about their module marks for the first mathematics module and their attitudes towards the two assessment methods, namely the coursework and the exam. The three students who had failed the module (all less well-prepared students) expressed feelings of unhappiness with regards to their module marks. In particular, this student expressed:

LWP 2: "I knew I could have done better, because I do know the work but I just go blank [in exams].”

This student clearly feels that his exam performance was not a fair reflection of his mathematical knowledge. Likewise, the remaining three less well-prepared students, who had passed the module, had expressed a preference towards the coursework assessment rather than the exam assessment. All six students described how they disliked the prospect of being examined in mathematics due to the pressure that accompanies this form of assessment. However, the coursework was highly favoured amongst these students.

LWP 1: "I liked the coursework...I could go away and research stuff. In fact I like that better than the exam because I learnt more from that."

LWP 2: "I like coursework ...I suppose it gives you the opportunity to prove that you've learnt the stuff."

LWP 4: "You'd put more effort into working on a 100\% coursework than you would revising for an exam.”

Recall, that the less well-prepared students, on average, had performed well in the coursework (average of 58.3\%). Moreover, they had performed better in this assessment than in the exam (exam average of 40.9\%). The above comments reflect the students' performances in the coursework and the exam, since the students feel more confident with the coursework assessment. This suggests that the exam assessment has certainly contributed to a lack of mathematics confidence amongst these students.

However, a common perception amongst the less well-prepared students, with the exception of the student who had performed well in the module, was that these students had no expectations of performing well in mathematics. During the interviews, these students had all expressed a desire to pass (achieve 40\%) the mathematics module rather than gain a high percentage.

When speaking about how the students felt they would perform in the second mathematics module: 
LWP 4: "I mean I would like to do reasonably well, but I look at it more pass/fail than as opposed to what level."

LWP 6: “I won’t be desperately upset if I don’t do especially well.” “I’m gonna have to try and scrape through... I'm gonna try and pass it.”

These comments reflect the general feeling amongst the less well-prepared students, and this reinforces the notion that the students have entered their degree program with little faith in their own mathematics ability. It is also likely that their results from the first mathematics module have helped to reinforce this negative attitude.

Analysis of the interview data suggests that the exam played a large role in undermining the confidence of the less well-prepared students. It also appears that the lack of mathematics confidence could have further repercussions for these students in the second year. Near completion of the second mathematics module, the students' attitudes do not seem to have changed, and it appears that they could enter their second year with the same negative perceptions of mathematics. When asked about the mathematics modules next year the students perceived the coming year in different ways. For example, these two students realise that more effort is needed in order to succeed.

LWP 3: "I'm gonna try and pass... I feel more confident in the physics modules, so if I put in more effort in them, I reckon I'll get more reward for it."

LWP 6: "I’m terrified because next year I've got to work so much harder. “

However, one wonders how these students define 'effort'. The students above need to do more than simply 'working harder' and will still need to adapt their learning strategies in order to ensure success.

On the other hand, this student clearly believes that if he continues in the same manner then eventually everything will become right and he will be at the same level as everyone else.

LWP 2: "I'm hoping that in time it will all start to fall into place. And then I'll be on the same level as everybody else."

This comment reinforces the lack of metacognitive skills amongst the less wellprepared students since this student conveys a lack of reflection on his learning and hence does not actively seek a way of adapting his learning strategy to ensure success. Finally, another student has no aspirations in mathematics and will continue his studies with the least amount of effort needed to pass.

LWP 4: "It's about getting through, whilst doing the least amount possible."

\section{Conclusion}

The use of qualitative data analysis has revealed that the students' experience of mathematics at university has had an impact on their attitudes towards mathematics and, in particular, on those students who have been deemed as mathematically less well-prepared. This paper has not examined the broader factors that may influence attitudes, such as gender, race, or social background, but it has looked at the way in which the students perceive mathematics and how these perceptions have changed throughout their mathematics education.

This research has shown that the perceptions of students who were identified as mathematically well-prepared differ from those students who were identified as mathematically less well-prepared. Data from the questionnaire has revealed that prior 
to university the well-prepared students generally enjoyed mathematics and felt confident with mathematics (57\% for each response). In comparison, the less wellprepared students did not particularly feel confident with mathematics (46\% indicated feelings of confidence) and fewer students (31\%) indicated that they enjoyed the subject.

However, the first semester experience of mathematics and the introduction of a support system has had an impact on the students' attitudes. Generally the wellprepared students' attitudes towards mathematics were reinforced since the questionnaire showed only a small change in feelings of both success and enjoyment in mathematics at university in comparison to their feelings of school mathematics. However, in terms of the less well-prepared students, their university experience had been mixed. Although feelings of enjoyment of mathematics increased amongst the less well-prepared students, their feelings of confidence have dropped rapidly. Further investigation, has revealed that in fact these misgivings relate primarily to the exam assessment since, as shown in Table 2, only $25 \%$ of the less well-prepared students felt confident with their exam attempt in comparison to $58 \%$ who felt confident in the module.

Data from the interviews suggest that the well-prepared students have adapted to university mathematics. However, the less well-prepared students have lacked the motivation and understanding needed to adjust to the new style of learning, possibly due to their negative attitudes towards mathematics. It was found that the less wellprepared students felt that they did not apply enough effort in their mathematics modules. These students expressed the thought that they should have worked harder during the first mathematics module. A major factor contributing to this lack of effort was the greatly reduced level of teacher support at university. Although the support initiative was designed to be similar to a classroom environment, rather than a lecturing environment, the nature of university meant that students were not under the same pressure to attend lectures or tutorials as they are at school. It appears that the students need support, enthusiasm and direction from a 'teacher' in order to understand the requirements of their new learning environment and to adopt successful learning strategies. By the time the students are examined, at the end of the module, the less well-prepared students must compensate for their lack of effort throughout the semester and therefore they chose topics that they felt confident with to learn for the exam. However, this usually proved unsuccessful, and a poor exam performance followed.

In conclusion, the analysis has shown that the well-prepared students had adapted well to mathematics at university. However, the less well-prepared students have found the transition more difficult. Generally, on completion of the first year, the less well-prepared Physics students lacked mathematics confidence and the ability to adopt an effective learning strategy. Furthermore, it appears that the less wellprepared students will enter their second year with a similar attitude towards mathematics and their learning strategies.

These findings suggest that less well-prepared students need additional support in the form of direction and ongoing monitoring during their first year at university. If students are aware of the expectations of university and are given continuous guidance, then this could ease the transition from school to university to help the students adapt to the new envirnoment. Another possibility is to assist students in monitoingr their own progress. This should engage students with the mathematics on their course and help them to direct their own learning accordingly. 


\section{References}

Aiken, L.R., Jr. (1976) Update on attitudes and other affective variables in learning mathematics, Review of Educational Research, 46, 293-311.

Feierabend R. (1960) Review of research on psychological problems in mathematics education, Research problems in mathematics education, Monograph No. 3. U.S office of education, 3-46.

Flavell, J. H. (1976). Metacognitive aspects of problem solving. In L. B. Resnick (Ed.), The Nature of Intelligence. Hillsdale NJ: Lawrence Erlbaum Associates.

Gal, I., Ginsburg, L. \& Schau, C. (1997) Monitoring attitudes and beliefs in statistics education, in: Gal, I. \& Garfield, J.B. (Eds) The Assessment Challenge in Statistics Education (Amsterdam: IOS Press and the International Statistical Institute).

Galbraith, P. \& Haines, C. (1998) Disentangling the nexus: attitudes to mathematics and technology in a computer learning environment, Education Studies in Mathematics, 36, 275-290.

Hofer, B.K \& Pintrich, P.R. (2002) Personal Episttemology. The psychology of Beliefs about Knowledge and Knowing. Mahwah NJ: Lawrence Erlbaum Associates.

L.M.S., I.M.A. \& R.S.S. (1995) Tackling the Mathematics Problem. Available online at: http://www.Ims.ac.uk/policy/tackling_maths_prob.pdf (accessed 1st March 2010).

Ma, X. (1997) Reciprocal relationships between attitude toward mathematics and achievement in mathematics, Journal of Educational Research, 90, 221-229.

Macrae, S., Brown, M. \& Rodd, M. (2003) The tale of the tail: An investigation of failing single honours mathematics students in one university. Proceedings of the British Society for Research into Learning Mathematics, 23(2), 55-60.

McLeod, D.B. (1992) Research on affect in mathematics education: a reconceptualization, in: D.A. Grouws (Ed) Handbook of Research on Mathematics Learning and Teaching (MacMillan, New York).

OECD (Organization for Economic Cooperation and Development) (2004) Learning for Tomorrow's World: First Results From PISA 2003. Paris: Author.

Pierce, R., Stacey, K., and Barkatsas, A. (2005) A scale for monitoring students' attitudes to learning mathematics with technology. Available online at: http://www.sciencedirect.com/science/article/B6VCJ-4FM9MHB1/2/1cfe41ed2473a8d93c9b7bad92aaa735 (accessed 1st March 2010).

Ruffell, M., Mason, J. \& Allen, B. (1998) Studying attitude to mathematic, Educational Studies in Mathematics, 35, 1-18.

Sutherland, R. \& Pozzi, S. (1995) The Changing Mathematical Background of Undergraduate Engineers (Engineering Council, London).

Symonds, R., Lawson, D. \& Robinson C. (2006) Retaining students with nontraditional mathematical backgrounds. Proceedings of the Fifth IMA conference on "Mathematics Education of Engineers", Loughborough University. ISBN 9780905091183.

Tapia, M \& Marsh II, G.E. (2004) An instrument to measure mathematics attitudes, Academic Exchange Quarterly. Available online at: http://www.rapidintellect.com/AEQweb/cho25344l.htm (accessed 1st March 2010).

Utsumi, M. C., \& Mendes, C. R. (2000) Researching the attitudes towards mathematics in basic education, Educational Psychology, 2, 237-244. 
Wenger, E (1998) Communities of Practice: Learning, Meaning and Identity.

Cambridge: Cambridge University Press.

[word count $=7495$ (including titles, abstract, references) 